\title{
CDTAs -based Current-Mode Multifunction Filter Employing Grounded Capacitors
}

\author{
Anisur Rehman Nasir \\ Associate Professsor \\ Uni. Polytechnic \\ Jamia Millia Islamia \\ New Delhi-25, India
}

\author{
S.N. Ahmad \\ Professor \\ Dept. Of Electr.\&Comm.Engg. \\ Jamia Millia Islamia \\ New Delhi-25, India
}

\begin{abstract}
In this paper, a new current-mode multifunction filter based on current differencing transconductance amplifier(CDTA) is presented. The proposed filter employs two current differencing transconductance amplifier (CDTA) and only two passive elements to realize lowpass and bandpass filter functions. The proposed filter have been tested with PSPICE simulation program. PSPICE simulation result confirms the theoretical analysis. The active and passive sensitivities are quite low
\end{abstract}

\section{General Terms}

Analog Filters , Active Building Blocks

\section{Keywords}

Current Differencing Transconductance Amplifier, Currentmode circuits, Multifunction, Signal processing

\section{INTRODUCTION}

The analog filters are used in high speed data communication for signal processing in cable modem, in regulation and measurement techniques, in electro acoustic applications. The circuits based on current-mode technique are suited for these applications. The current-mode signal processing circuits have many advantages like larger dynamic range, better linearity, high slew rate and higher bandwidth, simple circuit and low power consumption[1-2]. Several current-mode filter circuits are available in the technical journals using second generation current conveyor (CCII)[3], current feedback amplifier(CFA)[4-5], operational transconductance amplifier(OTA)[6-8], current differencing buffered amplifier(CDBA)[9] and operational transresistance amplifier(OTRA) [10] .

Recently current differencing transconductance amplifier (CDTA) have been introduced as new current-mode active analog building block suitable for current-mode analog signal processing application [11]. CDTA has two current inputs, two current outputs and electronic tuning by its transconductance gain. CDTA exhibits better performance such as higher speed and better bandwidth, free from parasitic input capacitances and electronic tunability. Some currentmode filters have been realized using CDTA as an active building block are reported in research journals.[11-20].

In this paper, a new current-mode filter using CDTA having single input and two outputs is presented. The proposed filter employ two CDTAs and only two passive elements which can realize low pass and bandpass filter functions simultaneously. The filter characteristics like natural frequency and quality factor can be electronically tuned through biasing current of the transconductance gain of CDTAs. Since the proposed filter contains grounded capacitors only which can be used for integrated circuit(IC) implementation. PSPICE simulation results are included to confirm the theoretical analysis.

\section{CDTA FUNDAMENTALS}

A current differencing transconductance amplifier(CDTA) consists of an input current differencing unit and two transconductance unit. The input stage takes the difference of input signals and converts to a voltage at the $\mathrm{Z}$ terminal through a load impedance. Then this voltage is converted to balanced current outputs with a transconductance parameter $g$ of the dual output transconductance stage. A circuit symbol of CDTA is shown in Fig.1, where $\mathrm{p}$ and $\mathrm{n}$ are two low impedance input terminal, $\mathrm{z}$ and $\mathrm{x}$ are output terminals. The characteristics equation of CDTA are given in ec*ntinn(1)

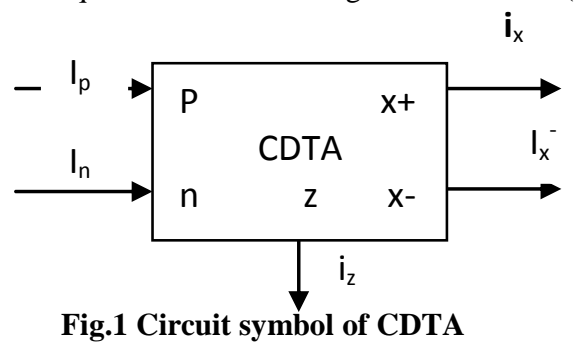

$\mathrm{v}_{\mathrm{p}}=\mathrm{Vn}_{\mathrm{n}}=0, \mathrm{Iz}=\mathrm{Ip}-\mathrm{In}, \mathrm{I}_{\mathrm{x}}{ }^{+}=\mathrm{gv}_{\mathrm{z},}$, and $\mathrm{I}_{\mathrm{x}}{ }^{-}=-\mathrm{gv}_{\mathrm{z}}$

where $g$ is the transconductance gain of CDTA. From eq.(1)current flowing out of the terminal $\mathrm{Z}$ is the difference between the currents through the terminals $p$ and $n$. The current flow though impedance $\mathrm{Z}$ results in voltage $\mathrm{VZ}$. The voltage at the terminal $\mathrm{Z}$ is transferred to a current $\mathrm{Ix}$ at terminal $\mathrm{X}$ by a transconductance $\mathrm{g}$ which is electronically controlled by an external bias current. The CDTA element can be realized by using CFA and OTA. The transconductance gain $g$ of the CDTA is directly proportional to the external bias current $\mathrm{I}_{\mathrm{BIAS}}$ which can be written as

$$
\mathrm{g}=\frac{\mathrm{I}_{\mathrm{BIAS}}}{2 \mathrm{~V}_{\mathrm{T}}}
$$

where $V_{T}=26 \mathrm{mV}$ at $27^{\circ} \mathrm{C}$ is the thermal voltage.

\section{PROPOSED CIRCUIT}

The proposed current-mode universal filter based on CDTAs is shown in Fig.2. The circuit employs two CDTA, and two grounded capacitors.,. Since all capacitors are grounded which makes filter attractive for integrated circuit(IC) implementation. The circuit analysis of proposed filter using characteristic eq(1) yields the following the current transfer function

$$
\frac{I_{2}}{I_{\text {in }}}=\frac{g_{1} Y_{2}}{Y_{1} Y_{2}+g_{1} Y_{2}+g_{2} Y_{1}+g_{1} g_{2}}
$$




$$
\frac{I^{-} x_{2}}{I_{\text {in }}}=\frac{g_{1} g_{2}}{Y_{1} Y_{2}+g_{1} Y_{2}+g_{2} Y_{1}+g_{1} g_{2}}
$$

If the admittances are $\mathrm{Y}_{1}=\mathrm{sC}_{1}$ and $\mathrm{Y}_{2}=\mathrm{s} \mathrm{C}_{2}$, the current transfer functions become

$$
\begin{gathered}
\frac{I_{2}}{I_{\text {in }}}=\frac{\frac{s g_{1}}{C_{1}}}{s^{2}+s\left(\frac{g_{1}}{C_{1}}+\frac{g_{2}}{C_{2}}\right)+\frac{g_{1} g_{2}}{C_{1} C_{2}}} \\
\frac{I^{-} x_{2}}{I_{\text {in }}}=\frac{\frac{g_{1} g_{2}}{C_{1} C_{2}}}{s^{2}+s\left(\frac{g_{1}}{C_{1}}+\frac{g_{2}}{C_{2}}\right)+\frac{g_{1} g_{2}}{C_{1} C_{2}}}
\end{gathered}
$$

The pole angular frequency $\omega_{0}$ and quality factor $Q$ of the proposed filter can be expressed as

$$
\omega_{\mathrm{o}}=\sqrt{\frac{g_{1} g_{2}}{C_{1} C_{2}}}
$$

$Q=\frac{\sqrt{g_{1} g_{2} C_{1} C_{2}}}{g_{1} C_{2}+g_{2} C_{1}}$

\section{NON-IDEAL ANALYSIS}

Taking non-idealities of CDTA into consideration, the terminal relations in $\mathrm{eq}^{\mathrm{n}}(1)$ can be modified as

$\mathrm{v}_{\mathrm{p}}=\mathrm{v}_{\mathrm{n}}=0, \quad \mathrm{i}_{\mathrm{z}}=\alpha_{\mathrm{p}} \mathrm{i}_{\mathrm{p}}-\alpha_{\mathrm{n}} \mathrm{i}_{\mathrm{n}}$ and $\quad \mathrm{i}_{\mathrm{x}}=\mathrm{gv}_{\mathrm{z}}$

where $\alpha_{\mathrm{p}}=1-\varepsilon_{p}\left(\varepsilon_{p}<<1\right), \quad \alpha_{\mathrm{n}}=1-\varepsilon_{n}\left(\varepsilon_{n}<<1\right)$, and $\varepsilon_{p}$ and $\varepsilon_{n}$ are current tracking errors from the terminal $\mathrm{p}$ to the terminal $\mathrm{z}$ and from the terminal $\mathrm{n}$ to the terminal $\mathrm{z}$, respectively. Taking the effect of the tracking errors into consideration, the natural angular frequency and quality factor are as follows

$$
\begin{aligned}
& \omega_{0}=\sqrt{\frac{\alpha_{n_{1}} \alpha_{n_{2}} g_{1} g_{2}}{C_{1} C_{2}}} \\
& Q=\frac{\sqrt{\alpha_{n_{1}} \alpha_{n_{2}} g_{1} g_{2} C_{1} C_{2}}}{\alpha_{n_{1}} g_{1} C_{2}+\alpha_{n_{2}} g_{2} C_{1}}
\end{aligned}
$$

The active and passive sensitivities of the proposed filter are listed as follows:

$S_{\alpha_{n_{1}}}^{\omega_{0}}=S_{\alpha_{n_{2}}}^{\omega_{0}}=S_{g_{1}}^{\omega_{0}}=S_{g_{2}}^{\omega_{0}}=-S_{C_{1}}^{\omega_{0}}=-S_{C_{2}}^{\omega_{0}}=\frac{1}{2}$

$S_{\alpha_{n_{1}}}^{Q}=S_{\alpha_{n_{2}}}^{Q}=S_{g_{1}}^{Q}=S_{g_{2}}^{Q}=S_{C_{1}}^{Q}=S_{C_{2}}^{Q}=-\frac{1}{2}$

Therefore, all the active and passive sensitivities are equal to less than unity in magnitude.

\section{SIMULATION RESULT}

The proposed CDTA based current mode universal filter has been simulated with PSPICE program. The CDTA active element was realized by using commercially available ICs i.e. CFA AD 844 and OTA LM13600. The power supply voltages used are $\pm 12 \mathrm{~V}$ and bias current is $\mathrm{I}_{\mathrm{BIAS}}=240 \mathrm{uA}$. The values of the passive components are chosen as $\mathrm{C}_{1}=\mathrm{C}_{2}=1 \mathrm{nF}$. Fig. 3 shows the simulation result of the proposed multifunction filter. The simulation results obtained agree with the theoretical analysis.

\section{CONCLUSION}

A new CDTA based current-mode multifunction filter is realized. The proposed circuit employs two CDTAs and only two grounded capacitors. The circuit realizes lowpass and bandpass filter responses from same circuit configuration. The circuit provides electronic control of natural frequency and quality factor. Since the circuit employs two CDTAs and two grounded capacitors, so it can be suitable for integrated circuit (IC) implementation The non-ideal analysis of the proposed filter gives quite low active and passive sensitivities. The PSPICE simulation results are shown. PSPICE simulation result confirms the theoretical analysis.

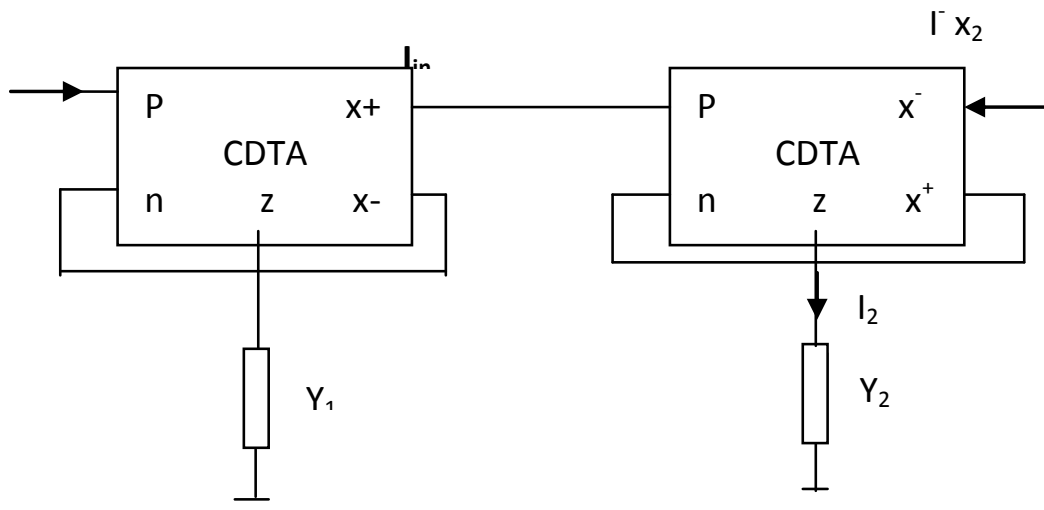

Fig.2 Proposed CDTA-based current-mode multifunction filter

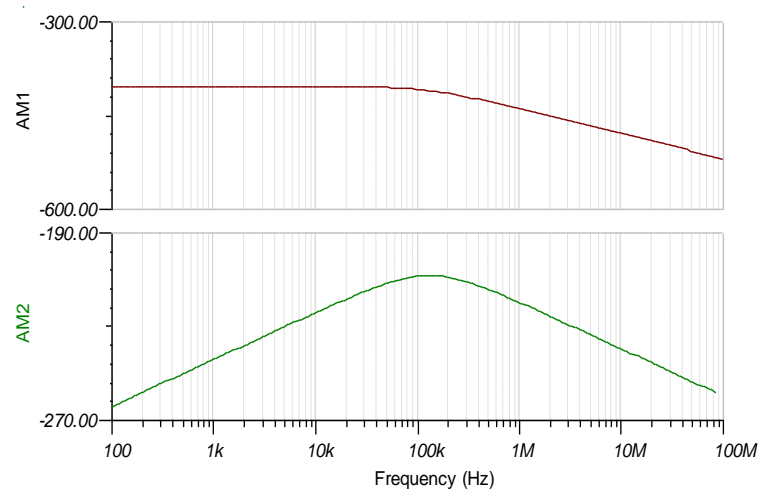

Fig.3 Frequency response of current-mode multifunction filter

\section{REFERENCES}

[1] Toumazou C, Lidgey F \&Haigh D(1990). "Analog IC Design: The current-mode approach", Exeter, UK, Peter Peregrinus

[2] B.Wilson,"Trend in current conveyor and current-mode amplifier design," Int. J. Electron., vol. 23, pp. 573-583, 1992.

[3] C.M.Chang, T.H.Houng, S.H.Tu, C.L.Hou and J.W Horng, "Universal active current filter using second generation current controlled conveyor," Int. J. of Circ. Syst. And Sign. , Proc. Vol.1,pp.194-198,2008 
[4] R.K. Sharma and R. Senani, " Universal current mode biquad using a single CFOA, “ Int.J. of Electronics,vol.91,pp.175-183,2004

[5] A.R. Nasir and S.N. Ahmad, "Minimum component current mode universal filter using current feedback amplifier," Int. conference on Advanced Computing \& Comm. Tech., Nov 08-09,2008

[6] X. Zheng, B. J. Maundy, E. I. El-Masry, and I. G. Finvers, "A Novel low-voltage operational transconductance amplifier and its applications," IEEEInt. Symp. Cir. Syst. ISCAS2000, Geneva, 2000.

[7] S.N. Ahmad, M.R. Khan and Moinuddin, "Operational transconductance amplifier based voltage-mode universal filter," Indian J. of Pure and Applied Physics, vol.43, 714-719, 2005

[8] A.Gokcen and U Cam, " MOS-C Single amplifier biquads using operational transconductance amplifier," Int. J. of Electronics and Commu," 63, 660-664,2009

[9] A.U. Keskin,"Multifunction biquad filter using single CDBA," Electrical Engg, 30,147-151,2004

[10] S. Kilınc, A. U. Keskin, and U. Cam, "Cascadablevoltage-mode multifunction biquad employing single OTRA," Frequenz, vol. 61, 2007,pp. 84-86

[11] D. Biolek, "CDTA-Building block for current-mode analog signal processing”, Proc. ECCTD'03, Cracow, Poland, , Vol. III, pp.397-400. 2003

[12] D. Biolek, V. Biolkova, Universal biquads using CDTA elements for cascade filter design. In: Proceedings of the CSCC 2003 Corfu, Greece, 2003,

[13] A.Ü. Keskin, D. Biolek, E. Hancioglu, E., and V. Biolková, "Current-mode KHN filter employing current differencing transconductance amplifiers", AEU International Journal of Electronics and Communications, Volume 60, Issue 6, pp. 443- 446. 2006

[14] T, Pongpisal, S. Unhavanich, W. Tangsrirat, W. Surakampontorn, " Cascadable current-mode filters using CDTAs", Proc.of 2009 APSIPA Annual Summit and Conference, Sapporo, Japan, Oct.,2009

[15] Tangsrirat, W. "Current differencing trans-conductance amplifier-based current-mode four-phase quadrature oscillator", Indian Journal of Engineering \& Materials Sciences,vol. 14, pp.289-294,August 2007

[16] W. Tangsrirat, T.Dumawipata, W. Surakampontorn, “ Multiple input single-output current-mode multifunction filter using current differencing transconductance amplifiers" Int J Electron Commu ; 61(4):209-14. April 2007

[17] NA Shah, M. Quadri and SZ Iqbal. "Realization of CDTA based current mode universal filter", Indian Journal of Pure \& Applied Physics, vol.46, pp.283-285, April 2008

[18] F. Karcar, H. Kuntman, "Anew, improved CMOS realization of CDTA and its filter applications", Turk J. Elect. Eng. \& Comp. Sci. vol.19, No.4, 2011

[19] A.T.Bebri and F.Andy, " $\mathrm{N}$ th-order lowpass filter employing current differencing transconductance amplifier", Proc. Of the 2005 European Conference on circuit theory and design, 2005

[20] N.Pandey ,Sajal K. Paul, "Single CDTA-Based current-mode all-pass filter and its applications Journal of Electrical and Computer Engineering vol.2011 